\title{
Mind the Mindstorms: Technocultures of Engineering Education in Three U.S. Elementary Schools
}

\section{Dr. Michael Lachney, Michigan State University}

Michael Lachney is an assistant professor of educational technology at Michigan State University. With expertise in qualitative social science methods, he is interested in the role that technologies can play in strengthening school-community relationships. He is currently working on educational technology design strategies and implementation tactics to help teachers enroll community-based expertise in culturally responsive science, technology, engineering and mathematics (STEM) education. In addition, his work aims to show how STEM can make contributions to everyday anti-racism in schools, with specific attention to engineering and computer science. 


\section{Mind the Mindstorms: Technocultures of Engineering Education in Three U.S. Elementary Schools}

\section{Introduction}

The LEGO Group's proprietary educational robotics kit, LEGO Mindstorms, has been included in numerous engineering education studies. An advanced search for "LEGO Mindstorms" in the American Society for Engineering Education archives reveals over 400 hits found within "document content." The amount of research that uses or at least mentions Mindstorms should not be surprising, given its popularity among engineering educators and teachers. As Eguchi [1] explains, the kit has been around in one iteration or another for two decades, allowing it time to become one of the most marketed and accessible tools for educational robotics. Despite its popularity, there has been little empirical work on Mindstorms as a cultural artifact. Given its popularity, what is the cultural significance of Mindstorms in education? And, how does this shape its meanings and uses in the classroom?

To give partial answers to these questions, this paper uses ethnographic data from three New York State public elementary schools to analyze the technocultural forms and uses of Mindstorms. The concept of technoculture is meant to make clear that the demarcations between technology and culture are fuzzy, what is technological is always already cultural and vice versa [2]. The concept may appear redundant since technology - i.e. "the set of practices that humans use to transform the material world" [3] —is always culturally situated [4] and value-laden [5]. Still, the concept is useful for making this explicit and avoiding confusion with more instrumental definitions of technology that are commonly employed in engineering.

I begin with some background on Mindstorms as educational technology and detail some existing literature on its uses in elementary education. This is followed by a theoretical overview of the concept technocultures, explaining how the concept is useful for understanding the cultural and technological politics of Mindstorms. I then contextualize this study in New York State during the 2014-2015 school year, when data for this paper was collected. I share methods for data collection and analysis before detailing the results. Looking at the similarities and differences of Mindstorms implementation across three different schools, as I do below, reveals how Mindstorms can help to enroll larger technocultures in teachers' lessons. But, these larger technocultures do not necessarily determine local instantiations. Accounting for these technocultural implications may better help researchers and pedagogues consider the moral and ethical implications of educational robotics in their work.

\section{Background}

\section{LEGO Mindstorms}

Named after a book by the famous educational technologists Seymour Papert [6], LEGO Mindstorms is a programmable robotics kit (see figure 1) that is produced and distributed by the multinational company, The LEGO Group. As a cultural artifact, it brings together the long legacy of construction kits for children (e.g. Lincoln Logs, K'NEX, etc.) with the symbolism and materiality of robotics from industry (e.g. iRobot, Boston Dynamics, etc.) and popular media 
(e.g. WALL-E, Transformers, etc.). Marketed for education and entertainment, the technological center of each unit is a programmable brick, which users can control with a programming language to manipulate specially made motors and sensors.

The programmable brick was first developed through a partnership between the MIT Media Lab and the LEGO Group in the 1980s. Resnick, Bruckman, and Martin [7] explain the brick's contribution to children's construction kits: "Traditional construction kits enable children to build structures like bridges and buildings. Contemporary construction kits (e.g. LEGO Technics) add power and motion, enabling kids to build motorized cars, Ferris wheels, an other battery-powered machines. The MIT Programmable Brick adds a third level—sensing and control." In the late 1980s, the programmable brick left the MIT Media Lab and early prototypes were made commercially available for home and school use through the marketing and distribution power of the LEGO Group. And, in September 1998 the official Mindstorms kits were released, selling out by December [8].

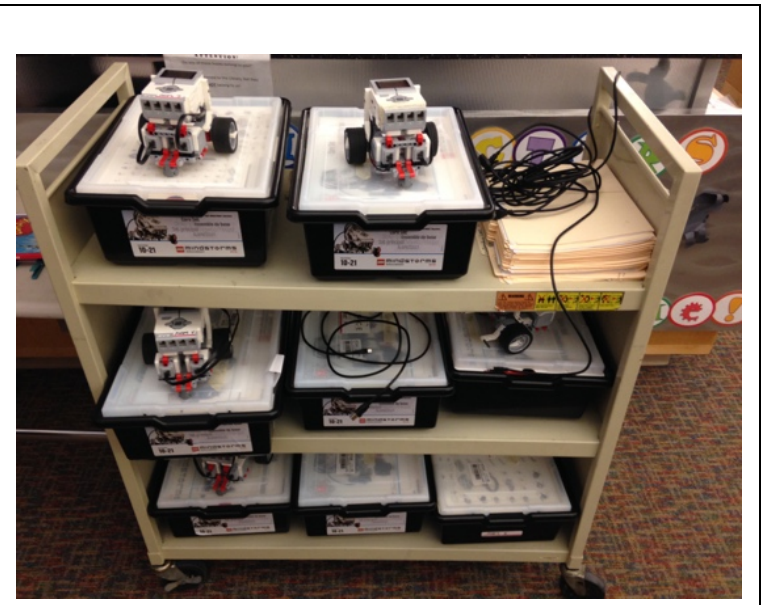

Figure 1. A cart of LEGO Mindstorms (EV3 generation), rolled out for an afterschool program.

Now in its third generation, ${ }^{\mathrm{i}}$ Mindstorms has become a popular way to introduce engineering design to young people in the United States and around the world. This is exemplified most prominently with the FIRST LEGO League (FLL), a partnership between the LEGO Group and the international robotics competition non-profit, For Inspiration and Recognition of Science and Technology (FIRST). In teams, young people compete against each other by programming Mindstorms to solve problems specified by FIRST for that year's FLL competition. According to FIRST's 2017 annual report [9], "Approximately 248,000 9-16 year-olds on 31,079 teams from 86 countries participated" in FLL. These numbers give a sense of the global reach of Mindstorms and its centrality in exposing young people to engineering.

\footnotetext{
${ }^{\mathrm{i}}$ To date, there are three different generations of Mindstorms that are demarcated by updates to the programmable brick. The first, launched in 1998, was the Robotics Command eXplores System (RCX). The second was the NXT, released in 2006, and the third, released in 2013, was the EV3.
} 


\section{Mindstorms in Elementary Education}

It would be a mistake to assume that FLL alone accounts for the educational success of Mindstorms, or that its use is restricted to ages 9-16. While most often used outside of the traditional school day, Mindstorms has also been used in formal engineering education at levels that range from undergraduate [10] [11] to elementary [12] [13]. Educational robotics in elementary education, and kindergarten and prekindergarten specifically, are studied much less than in successive grades [14]. However, with engineering entering schools through the Next Generation Science Standards and the growing recognition that elementary education is an important part of the science, technology, engineering, and mathematics (STEM) pipeline, it is likely that there will be increased attention to robotics in elementary education in the coming years.

Eguchi [1] explains that in the U.S., Mindstorms is most appropriate for elementary and middle school students. In the elementary context (i.e. K-5), Rogers and Portsmore [15] argue that Mindstorms helps students engage in engineering design that supports learning concepts from physics, programming, and mathematics much earlier in their development than what is traditionally expected. What is more, they support the idea that the technology encourages differentiated learning in the classroom as activities and materials can be modularly extended; that is, Mindstorms has "low entry and high ceilings" that allow students easy access for use, but sustained, personalized engagement based on their own interests and technical knowledge levels [15].

Research on the use of Mindstorms in elementary education suggests that the technology is not only of interest to students because of its playful familiarity as a toy, but may also increase their academic achievement in STEM. Reporting on the results of implementing Mindstorms for seven years in one elementary school, Varney et al. [12] provide anecdotal evidence to suggest that students who used Mindstorms during STEM lessons had a full letter GPA above those who did not. Positive changes in students' standardized test scores were also reported, with less than half scoring proficient in mathematics before the program was introduced to the majority scoring proficiently afterwards. These findings are consistent with a study by Wendell and Rogers [16] that suggests elementary students' engagement with engineering design via Mindstorms increased their science content knowledge. However, they also found little change in students' attitudes toward science. Indeed, while the majority of studies suggest that educational robots can enhance learning, the claim is still controversial as some show no changes at all [14].

\section{Technocultures}

For all the work on educational robotics in general and Mindstorms specifically, there are few studies that draw attention to the cultural implications of Mindstorms [17]. Some research on broadening the participation of women in STEM mentions how the technology is traditionally "masculine associated" [18]. Other studies have explored how Mindstorms is implicated in the politics of neoliberalism [19] [20]. Yet, these studies only mention the cultural aspects of Mindstorms in passing or contextualize it within the larger political economy. 
To fill this gap, this paper uses the concept of technocultures as a lens through which to analyze Mindstorms at the grounded, everyday symbolic and material levels of the school. The concept of technocultures is inherently political [2]; it speaks to the "arrangements of power and authority in human associations as well as the activities that take place within those arrangements" [5]. Instead of a functionalist focus on Mindstorms as technology that can aid in students' academic achievements and interests, I study the ways that teachers and students talk about Mindstorms, how this shapes their experiences with it, and how those experiences are materially expressed as education.

The concept of technocultures presupposes the indeterminate and interdependent co-construction of technology and culture [2]. Technology and culture always implicate each other, in that "technology is always already cultural and culture is always already technological" [21]. The concept is not only meant to describe this interdependence, but also how this interdependence is symbolically and materially realized. Shaw [22] explains that, "We can therefore describe the study of technoculture as an enquiry into the relationship between technology and culture and the expression of that relationship in patterns of social life, economic structures, politics, art, literature, and popular culture." In other words, the study of technocultures identifies relations between technology and culture, and then how they interact and co-construct one another. Through the lens of technocultures, teachers' and students' relationships with Mindstorms can be studied at three levels: 1) how they perceive the educational value of Mindstorms; 2) how those values align with the cultural politics of robotics and engineering; and 3) how those values are symbolically and materially expressed in schools.

\section{Context, Participants, and Methods}

\section{Context}

With IRB approval, this study took place across three classrooms at different elementary schools in New York State during the 2014-2015 school year. I first met the three teacher-participants during a summer professional development workshop at a technical university. The workshop consisted of elementary and middle school teachers and had an explicit focus on connecting the EV3 generation of Mindstorms and the visual programming language that comes with it to classroom and curricular goals, specifically those of STEM. As part of the workshop, participants designed curriculum modules and lesson materials to meet these goals, with the idea that they would implement them the following school year. With a strong top-down push for integrating the Common Core State Standards into classrooms, mathematics connections were emphasized by the program and many of the teachers. Still, the choice to use Mindstorms was justified by the university program's mission to use engineering design to support STEM more broadly across $\mathrm{K}-12$ settings.

Because the university program recruited from a diversity of surrounding districts, the workshop participants represented schools that serve communities with different ethnic demographics and socio-economic statuses. The schools where the three teachers in this study worked represented these differences. Using 2014-2015 data from the New York State Education Department, table 1 represents the three schools. To protect the identities of the teachers and students, I have used 
pseudonyms for the school names and rounded the numbers down within a ten-point range of the actual percentages.

Table 1. Selected demographics of the three schools where the teachers worked in 2014-2015
\begin{tabular}{|l|l|l|l|}
\hline School Pseudonym & Students of Color* & White Students & $\begin{array}{l}\text { Economically } \\
\text { Disadvantaged } \\
\text { Students }\end{array}$ \\
\hline $\begin{array}{l}\text { Old-Time } \\
\text { Elementary }\end{array}$ & $>30 \%$ & $>60 \%$ & $>20 \%$ \\
\hline $\begin{array}{l}\text { Middle-Town } \\
\text { Elementary }\end{array}$ & $>70 \%$ & $>20 \%$ & $>60 \%$ \\
\hline $\begin{array}{l}\text { Crossroads } \\
\text { Elementary }\end{array}$ & $>20 \%$ & $>70 \%$ & $>10 \%$ \\
\hline
\end{tabular}

*Here "students of color" is used to represent five "ethnic" enrollment categories used by the New York State Department of Education: "Black or African American," "Hispanic or Latino," "Asian or Native Hawaiian/Other Pacific Islander," and "Multiracial."

Unlike middle and high school teachers, elementary teachers are responsible for teaching across the curriculum. This gives them more options to connect Mindstorms to their classroom lessons. Unlike, say, a middle school math teacher who is only concerned with how Mindstorms connects to math content, elementary teachers might find Mindstorms useful for math, science, or other subjects. At the same time, these teachers are still responsible for meeting state expectations, especially when it comes to subjects on which the state tests (i.e. mathematics and English language arts), and often prioritize these lessons to keep up with the timeline the district has established.

\section{Participants}

While there were some differences about when, where, and how Mindstorms were implemented across the three schools, all the teachers expressed a general interest in exposing students to robotics, computer programming, and engineering. They had support not only from the university professional development program but also other teachers in their buildings who were using or interested in Mindstorms for their own classrooms. In addition, all teachers used building directions, or slight variations of them, and the programming language that comes with each EV3 Mindstorms kit.

At Old-Time Elementary, Bob, ${ }^{\text {ii }}$ a White male $4^{\text {th }}$ grade teacher, implemented Mindstorms as part of a geometry lesson during regular school hours. The goal of the lesson was for students to program the robot to move around the perimeter of a rectangle, made out of tape that was stuck on the ground. The lesson took place over three days during one week and supported his existing geometry units. In his classroom, Bob taught students to adjust for degrees, tire rotations, and seconds in the visual programming language, providing them with the basic knowledge to make the robot run the perimeter. While the lesson started off in his classroom, eventually the students moved to a computer lab down the hall where, in small groups, they had more room to program and run the robots on their own.

\footnotetext{
ii All names have been changed to pseudonyms to protect the identities of research participants.
} 
Deborah is a Black female $4^{\text {th }}$ grade teacher at Middle-Town Elementary. She implemented Mindstorms on Wednesdays, after-school for about two months. The club also met one other day during the week with another teacher. Deborah treated after-school implementation as a pilot program that might lead to in-school programming or more after-school programs in the future. In this more informal setting, the program was less focused on curricular content and more so on learning the building and programming skills to make the robots "move forward," "lurch," "pirouette," and more. Beyond socializing with friends and playing with computers, a motivating factor for attending the program was the possibility of earning a "Robotics Club License," which indicated students had successfully completed a checklist of these movements by programming one of the robots. The program took place in the school library, which included a computer lab. In groups of two and sometimes one, students had room to move around, experimenting with different programs and inputs as they worked their way through the checklist.

Jill, a White female $3^{\text {rd }}$ grade teacher, implemented Mindstorms at Crossroads Elementary during the school day. Like Bob, she connected Mindstorms to a geometry lesson on measurement, specifically different ways to program the robot to move one meter forward, using tape on the ground to measure distance. Lessons were scheduled for most Mondays over the course of about two months. Like Bob's lesson, it supported learning spatial and temporal measurements, introducing math concepts afforded by the hardware and software: degrees, seconds, rotation, etc. Jill taught students the basics to move the robots forward and then let them build and program the robots on their own. Jill's classroom was spacious and provided ample room for students to spread out, working in groups of three or four, without running into each other.

\section{Data Collection and Analysis}

Across these three schools, data were collected using the ethnographic methods of participant observation and semi-structured interviews. Field notes, pictures, and audio recordings were collected from classroom observations. This multimedia data collection helped to fill in my notes, as I was often asked by teachers and students to help work through some of the pedagogic and technical aspects of implementing Mindstorms. After observing implementation in the classroom, 30min-70min semi-structured interviews were conducted with each teacher. These three interviews were audio recorded and transcribed for analysis.

Field notes, interview transcripts, and pictures were uploaded to the computer assisted qualitative data analysis software, NVivo. Interview transcripts were then analyzed using a "descriptive" coding method in which excerpts from the text were tagged with a word or phrase to summarize its meaning [23]. These codes were then "triangulated" [24] with field notes and pictures to verify teachers' comments and claims. Codes were then aggregated under three themes designed to help answer the research questions above: 1) the perceived educational values of Mindstorms; 2) connections to engineering and robotics outside of the schools; and 3) the symbolic and material expressions of those values and connections in the schools.

\section{Findings}

Educational Values of Mindstorms 
Bob, Deborah, and Jill shared common values when it came to the role of Mindstorms in their students' education, but encountered different barriers and constraints when trying to support those values. In common, they valued Mindstorms for two general reasons: 1) its role in supporting project-based learning; 2) its potential role in shaping students' futures, specifically the possibility that they might choose to pursue engineering, robotics, or another STEM field.

The perceived additive value of Mindstorms to their schools is its support for hands-on, projectbased learning. While sometimes this is framed by the fact that Mindstorms is a toy that references popular youth culture, the larger focus was on its role in changing the content and structure of instruction. For example, Jill compares lessons with Mindstorms to her normal school day: "The LEGO Mindstorms is more project-based I guess. And I have been trying to increase the amount of projects that the students are working on." Indeed, the pedagogic value of Mindstorms was commonly articulated through opposition to more traditional classroom instruction. As Bob put it, "... if it's a direct instruction [students] are not going to remember it as well, so for me, I think there should be more of it. A lot more of it...involving the robots and whatever." But this attitude was not consistent across the three teachers.

Without diminishing the value of project-based learning that Mindstorms affords, Deborah explained how the after-school program may have leaned too far away from direct instruction, making some of the tasks (e.g. programming) difficult for students to grasp:

...just more of a structured way to teach each aspect of the programming, because I think... that's what [the students] had the most difficulty with...I think part of that was because it was more exploratory versus more structured...on one hand it's good for them to be challenged and work through and sweat it through but the other hand, maybe just a little more instruction.

Teachers adjust and negotiate instruction for different spaces, accounting for and prioritizing various stakeholders' expectations depending on the context. The after-school space can be more open-ended and uncertain than a traditional classroom. Given the voluntary nature of Deborah's after-school program, and many others like it, greater attention can be given to students' desired ways of learning. Though, as Deborah explained, this does not suggest that after-school projects equate to laissez-faire education. They still require expert instruction.

With this project-based emphasis, teachers found opportunities to integrate STEM content that is not district mandated, primarily engineering design and programming. For example, Bob has an engineering background and found that Mindstorms allowed that to be a classroom asset: "...my background is in engineering, I think that probably helps a lot. And I have always been one to tinker and build. I have always had kids do that." Jill also had connections to engineering, with her husband being in the professions and her pre-college daughter taking it up as an interest. Jill explained how she conceptualizes the role of engineering in Mindstorms lessons,

I look at engineers as having a problem and trying multiple ways to try and solve that problem. So, that's my basic level of engineering and these students kind of ran with it. This is what we need to do, let's try this, okay, no, no, that didn't work, let's try this. 
Unlike Jill's and Bob's schools, Deborah's school serves a majority of students who New York State classifies as "economically disadvantaged." This seemed to have influenced her perceptions of students' exposure to certain technologies and STEM topics,

Very few are more familiar with LEGOs and robotics and so it was very new to them... you know low socioeconomic[s]... It's not surprising because they do not have that type of exposure and so it's really important and I think was fascinating for them to have that exposure to see what STEM is all about and they seem to really enjoy it.

It appears taken for granted that Jill's and Bob's students are familiar with LEGOs, and some even Mindstorms. In contrast, Deborah's consideration of the social and economic inequities that her students face does not allow her to make such assumptions.

Teachers found the STEM connections educationally important in and of themselves, but also articulated hopes that they inspire students to learn more about STEM and possibly choose it as a future career. While these hopes were future-oriented, they were also intentionally part of the lessons and activities. Jill explained her hope that students will take on STEM identities while engaged in classroom work,

I would love for them to start to be little engineers where they are keeping their own little engineering notebook and saying okay this is how I'm going to make a table, this is what the table is going to look like and then make the graph afterwards.

By putting students in the position of STEM professionals in the classroom, Bob had similar hopes, "And so, hopefully, and maybe no one will from there, but I hope some of the kids there...maybe they will want to be a programmer, maybe they want to design robots, who knows." He has had direct experience in realizing how his actions can inspire students to pursue STEM beyond PK-12 education. Discussing a soap box derby race that some of his students continue to participate in, Bob recalls,

I was buying flowers at the place right... my wife wanted flowers and some kid walks in and say[s] "hey"... I said "yup" and he said, "I'm a senior in college for mechanical engineering... because of the soap box derby."

In explaining these hopes for their students, Jill and Bob emphasize their own role in encouraging students to enter the STEM pipeline. In addition to Mindstorms and herself, Deborah put emphasis on the whole community in school and beyond. She explained,

...everyone in the community is invested in our future. So, it's all hands on deck. So, hopefully that encompasses, you know, participation is soliciting the involvement of, you know, whoever and whatever is needed to move our children to a place where they can be positive contributors to our future society. They're our future, so it's... everybody needs to delve in and do what they can to support them. 
The urgency in which Deborah speaks may reflect a crisis in the underrepresentation of students of color (e.g. African-Americans, Latinx, and Native Americans) in STEM fields.

The economically advantaged and predominantly White students that Jill and Bob serve are already in a privileged position to enter the STEM pipeline. Given the long history and ongoing problem of White supremacy that structures participation in STEM fields, Deborah's quote speaks to the need for societal change that will not come about from one teacher or individual. In this way, the educational value that Deborah places on Mindstorms is not only about one individual making it as a mechanical engineer but is also about overcoming the racialized and structural exclusion of Black and Brown communities from participating in STEM knowledge production. It is not that Jill's and Bob's students lack community support, but that the social, cultural, and financial capital that make STEM participation more likely in higher-income communities can be hidden by narratives of personal inspiration, however important they may be for young people to hear.

\section{Outside Connections}

When discussing possible ways to excite students about STEM, the three teachers proposed field trips and guest speakers that they may include as part of their future Mindstorms lessons. The emphasis that they placed on what and who might best accompany these lessons varied, aligning with their goals to inspire future STEM professionals.

While Jill appreciated the robotic qualities of Mindstorms, she placed greater emphasis on the possibility that it might motivate students' interactions with STEM professionals who can speak to the hands-on applications of their knowledge. She was specifically interested in professional practices that might resemble students' experiences when working with Mindstorms. When discussing a possible guest speaker Jill explained,

I would definitely bring in some type of engineer. It doesn't even have to be with robots... have them bring in something hands-on, but somebody that's worked on something but had mistakes along the way. Somebody that said I tried this and this is what happened, so then I thought - you know somebody that could think them through how they were persevering through their project and again, this would be tying in the math like where they used math along the way. Because I really think that kids when they go to school, they are thinking again that math is so linear, this is the day I do this kind of skill, this is the day I do this kind of skill and when it just comes all together, when you kind of have to know oh, I know how to do that. I know how to do that.

Here Mindstorms is used to construct a specific image of engineering, one that is polytechnic and project-based, bridging the STEM disciplines that traditional schools keep siloed. In other words, Mindstorms helps represent STEM as Jill assumes it exists in professional life. This helped her align classroom activities with an interdisciplinary representation of STEM, exemplified as engineering.

Bob was also interested in connecting Mindstorms to the professional world of STEM, but places greater emphasis on the direct application of other robotics technologies. He finds connections to 
industry, specifically industry automation. For example, he explained a field trip idea he had after learning about an automated factory in a neighboring district,

I was very excited about it. I hear, I have never been there myself, but I hear it's all robotic. I hear the owner is very like into education and very excited about his plant... I know that that was a business there, the business burned down... and got rebuilt heavily with robotics. So, I think of all the things that could go in that. So, like what happened to the workforce? It was rebuilt with robotics, what happened? And just okay, it's a business, what did this guy, how did he get into this business? I mean kids like somebody, [who] owns a factory that makes insulation, like how did he get there? I mean I think it's important for kids to hear all those things, like people get to places with very intended consequences and people get there with no intention whatsoever, it's just where life brought them but opportunities arose, like you think okay, your factory burned down that's not an opportunity but maybe it was because now it's his - he did robotics for a reason, is it more cost efficient? Is it a better product?

Bob wanted students to see how robotics applications can support flexibility and adaptability in professional life. What is more, he introduced interesting questions about automation and labor, some that could help students engage the ethical and moral dimensions of robotics. Yet, the narrative he constructed is ultimately from the perspective of the business owner who profits from technological unemployment. It may be the case that questions about the negative intended and unintended consequences of STEM might be difficult for teachers to navigate and may even appear contradictory if the goal is to inspire entry into affiliate careers.

Considering her students' age and interests, Deborah proposed that an older student or a robotics team might be appropriate guest speakers. She explained her rationale,

I would probably have another student... an older student who's been part of the robotics program come in and show like where this can go, how big can you get, even I know in the high school the robotics it's huge, so you know student or the team from there coming in and presenting... [these] children, specially the elementary level are in the here and now and it's really hard to extrapolate and see then so far into the future and that's developmental, but I think that would go a long way and continuing to cultivating, maintain that interest that the students could have in robotics.

The quote may suggest that Deborah is concerned with providing immediate avenues for youth to continue their engagement with robotics. Having a young person or a group of young people, closer to the age of her students, come in as guest speakers may be perceived as much more relatable than an engineer or business owner who may not have direct connections to the community Deborah's school serves. The teachers' varying preferences for outside connections present interesting questions for STEM educators and researchers: is it more effective to present STEM knowledge as something outside of the immediate community or something that is embedded in a localized context? What is most effective for the goals of broadening the participation of underrepresented students in STEM? And, how does the materiality and symbolism of Mindstorms support or inhibit these goals? 


\section{Expressions of Values and Connections}

In each school, the look and work of project-based learning, intimately connected to the teachers' hopes of inspiring future STEM professionals, is largely shaped by not only the material affordances (and limitations) of Mindstorms but also the computers required for programming and the spaces where those computers are used. Recognizing the financial costs of Mindstorms and the computers that house the EV3 programming environment, each of the teachers had techniques for managing students' activities and, sometimes, excitement when working with the robots. Bob explained how he manages excitement during lessons with Mindstorms,

...it's okay to be excited, but if that excitement often comes, you are louder then the next person, is louder because they are trying to hear or "oh look it's over here" and they just stepped on somebody's robot... [I] just keep reminding them that there's other things around, other kids' robots are around...like don't leave your box of Legos on the desk because it can fall off. Put it on the floor because it can't fall off the floor.

While Bob's techniques do not make the activity any less project-based (i.e. simulations of realworld problem-solving and collaboration), they are reminders that project-based learning can fall on a continuum of high-structured to low-structured activities. Indeed, the image of project-based learning as being motivated by students' own explorations is also challenged by the builds of the robots themselves.

The build and look of the robots were completely uniform within each school and generally the same across schools. It may be concluded that standardized curriculum led to the material standardization of the builds. While there is some truth to this claim, it is ultimately too simplistic. The uniformity largely followed from teachers relying on the build directions, or variations of them, that come with the kit, as well as standardizing the builds to make sure students could complete their assigned tasks in ways that helped teachers anticipate and troubleshoot problems. There was some variation between Bob's builds and Deborah's and Jill's builds. Bob positioned the programmable brick closer to the ground with the motors and wheels coming out from the sides, while Deborah and Jill positioned the brick on top of the motors.

These uniform builds upset commonly held assumptions about the educational value of LEGOs, but are rather consistent with their commercial expectations of play. As part of a long line of construction kit toys, the modularity of LEGO products, open to forward and backward compatibility, means they can be mixed and matched in creative expressions of youths' (and adults') design ideas and goals. Akin to the tradition of "adventure playgrounds" [25] [26], where self-directed play and spontaneity are the primary goals, LEGOs afford trial-and-error experimentation and exploration in design, with no right or wrong answers. At the same time, LEGO kits and toys are sold by packaging certain quantities of bricks and pieces to make specific designs, whether that is a medieval castle or Star Wars battle station. Each package comes with step-by-step directions for building what the LEGO designers intend with their assemblage of bricks and pieces; in other words, they present a specific, correct way to build. So it is not that the teachers were using LEGOs in unauthentic or unintended ways - both support project-based learning - but that the ways that made sense for their individual classrooms is more consistent with their intentions and those of LEGO designers, not necessarily students. 
This is not to say that the teachers were agnostic to their students' interests, concerns, and positions within their classrooms. In fact, how the teachers positioned students when using Mindstorms intentionally aimed to invoke an immediate sense of STEM participation, invoking connections to outside engineering and robotics during implementation. Indeed, STEM participation was not always framed as something that takes place in the future; that is, something that happens in or after entering the STEM pipeline. Its mere use in schools was perceived as part of larger innovative trends in STEM, in which students were told they are participating. Each teacher, in their own way, framed the use of Mindstorms in terms of the growing field of educational robotics, which appeared alongside applications in economic, political, and social life. Unlike more common pathways for disciplines to enter schools, Mindstorms is seen as a direct application. Compared to, say, mathematics, where its educational application is framed on the periphery of the actual disciplinary innovations, students were told that Mindstorms is an innovation of the robotics discipline in and of itself, like those in the military, healthcare, and industry.

To make these points, teachers drew on resources from their shared professional development and own social capital, weaving this narrative into the building, programming, and use of Mindstorms. For example, while broken during the duration of this research, Bob had a Roomba from the iRobot company - that, during 2014-2015, made domestic and military robotics

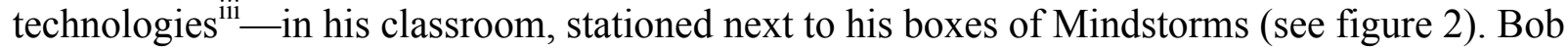
explained how he connects his Roomba to the Mindstorms lessons,

Unfortunately, my Roomba died, it doesn't work anymore, but we did write a donor...trying to get funded for a new one, but yeah because then you can say well is that a robot? So, a lot of kids are like "no," they think like a robot is like something walking and talking and like and so it just kind of brings [in] the conversation like robots are, somebody had a program to do that. It has the sensors to do that, like all of the things that are, you think the carry over between that and the LEGOs, anything on the LEGOs is on that. You know whether the sensors and the robots power one wheel and another wheel and turning...so you can just introduce the idea of robots with that "hey, we have a robot." Like what is a robot? And then just the idea of somebody programmed that, you are programming this.

Bob brings up important questions about what robots are, what goes into making them work, and what work they can ultimately do, questions that help to demystify computing technologies and may even help students explore what it means for something to be alive, in turn reflecting on themselves and their relationships to living and nonliving actors [27]. The fact that the Roomba had "died" and required fixing from outside donors — not from the school—adds a number of technocultural dimensions for considering these questions, including funding for upkeep, as well as planned and unplanned obsolescence.

Deborah and Jill also introduced Mindstorms by connecting it to other robotics technologies. For example, they both showed students a video of the DARPA funded Cheetah robot, made by

iii iRobot sold off its military research and development branch in 2016. 
Boston Dynamics, alongside other examples of robots from industry, military, healthcare, and, most relevant to their case, education. During the Boston Dynamics video, students in Deborah's class laughed at the robot, commenting on its legs while it ran on a treadmill. While these examples of robots engage students' curiosity and excitement, beyond general categories there was little discussion of their specific uses.

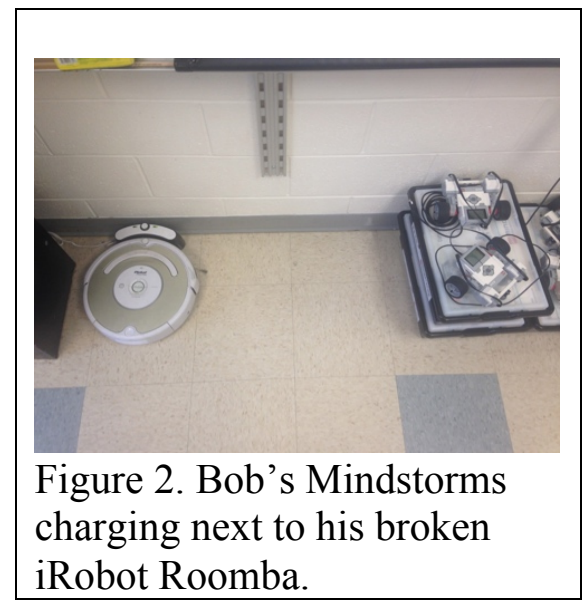

How might teachers' and students' knowledge of the Cheetah robot as a war machine change their perspectives? How might this influence teachers' instructions? What might they learn when comparing the Cheetah to robots that are used to help the elderly or for rescue missions? While teachers might desire to put on an air of neutrality when introducing the violent and caring uses of robots, doing so is a missed opportunity for not only developing more intentional critiques of robotics but also more intentional celebrations. This may help students and teachers alike consider what they want from robotics technology and how specific companies do or do not align with their own values. Essentially, what would it mean to incorporate the moral and ethical dimensions of robotics into teachers' and students' work with Mindstorms?

\section{Discussion}

Each of the three teachers enrolled the larger technocultures of automation and robotics into their schools. However, these larger technocultures did not necessarily determine local instantiations. Teachers had their own values and connections to make Mindstorms relevant to students, shaping its meanings and uses. The technocultural expressions of engineering education in these three schools is shaped by the interplay between the material affordances of Mindstorms, school schedules and spaces, curriculum demands, and structural inequities. Mindstorms could be used for free-form play that is based on students' interests and desires, or structured in such a way that supports multiple builds. But, in the cases above, the interplay between these material and structural forces constructed them as uniform, fitting in with the teachers' expectations, goals, and time constraints. Regardless, the connections to these larger technocultures offer opportunities that are often missed; opportunities to encourage students' critical reflection on what they—or perhaps their communities—want from robotics research and development. What might an ethics of robotics for elementary students look like? And, how might this support teachers' instruction with robotics? 
While future research is needed, perhaps the claim that Mindstorms, and other technologies like it (e.g. Logo, makey-makey, etc.), break down the concrete/abstract developmental binary for learning STEM ideas [6] [15] is also true for ethics. One promising framework that has found attention within the engineering education community is the ethic of care [28] [29]. The moral orientations of elementary-aged young people have been studied and debated, with claims about gender differences invoking much controversy [30]. Ethical caring demands forming relationships, which allows differences, whether gendered, racialized or socio-economic, to be negotiated, case-by-case at the everyday level. Like many ethical traditions it seeks to limit violence and maximize well-being; but unlike others it begins by "dismiss[ing] the old distinction between is and ought as a pseudoproblem," reorienting ethics toward physical life and lived experience [31]. As opposed to basing ethical decision making in "logico-mathematical reasoning," an ethic of care is rooted in relationships between the "carer" and the "cared for," with an emphasis on the carer being accountable to the cared for [31].

Most exciting from a pedagogical point of view is the focus that an ethic of care places on physical life and lived experience. The experiential element of ethical caring offers opportunities to consider new roles for narrative and performance in highlighting issues such as technological unemployment during Mindstorms building and programming. Considering the centrality of anthropomorphization and morality in children's fables, one could imagine elementary teachers drawing on cultural and literary studies that address these issues [32] [33] while writing or having their students write fables that not only have human-like animals but also sentient machines. Building on the history of kinesthetic learning and Mindstorms [34], students may find ways to act out these fables, programming their robots as part of skits, dances, or other movement-oriented forms of expression.

Examining robotics through an ethic of care may not only help teachers make ethical issues surrounding automation [35] and military robotics [36] concrete and age appropriate for their students, but also explore how these issues intersect with their own labor and workplaces. For starters, educational technologies have a long history of military connections and ties [37], which can help teachers understand the current interest of DARPA and military recruiters in STEM education [38]. But reflecting on these relationships through an ethic of care is only the tip of the iceberg. With artificial intelligence and machine learning being posed for integration into education and schooling [39], teachers' unions and university programs will need methods to prepare teachers to advocate for themselves in the face of technological change.

\section{Conclusion}

LEGO Mindstorms is widely used in engineering education and engineering education research. Despite this fact and with few exceptions, there has been little work on its cultural significance within engineering or STEM education more generally. For these reasons, this paper posed two questions: 1) what is the cultural significance of Mindstorms in education? and 2) how does this shape its meanings and uses in the classroom? To answer these questions, I highlighted the fact that technology and culture are already always co-constructing each other with the concept of technocultures. This concept provided a lens through which to study three teachers' understandings and implementations of Mindstorms in their schools. 
To answer the first question, I found that the cultural significance stemmed from how teachers enrolled the larger technocultures of engineering, automation, and robotics into their lessons. This was intimately connected with their hopes that students' will enter the STEM pipeline. But, in answering the second question, these larger technocultures did not determine the localized meanings and shapes of these three instantiations. Teachers used Mindstorms in ways that spoke to their own values and social connections, which were shaped by school schedules and spaces, curriculum demands, and class and racial inequities.

These local instantiations provide opportunities to consider the moral and ethical dimensions of larger technocultural issues (e.g. technological unemployment, autonomous vehicles, or military robotics) and their relationships to education. As a framework for considering these technocultural ethical issues, I introduced an ethic of care for teachers to not only innovate school lessons but also make judgments about their own labor and workplaces. Future research in educational robotics may look at how Mindstorms can be used to break down the concrete/abstract dichotomy for ethics, just as it has sought to do with STEM ideas.

\section{References}

[1] A. Eguchi, "Bringing Robotics in Classrooms," in Robotics in STEM Education: Redesigning the Learning Experience. M. S. Khine, ed. Cham: Springer, 2017, pp. 3-31.

[2] C. Penley, and A. Ross, Technoculture. Minneapolis: University of Minnesota Press, 1991

[3] E. Schatzberg, Technology: Critical History of a Concept. Chicago: University of Chicago Press, 2018.

[4] R. Eglash, A. Bennett, C. O'Donnell, S. Jennings, and M. Cintorino, "Culturally Situated Design Tools: Ethnocomputing from Field Site to Classroom." American Anthropologist vol. 108.2, pp. 347-362, 2006.

[5] L. Winner, The Whale and The Reactor: A Search for Limits in an Age of High Technology. Chicago: University of Chicago Press, 1986.

[6] S. Papert, Mindstorms: Children, computers, and powerful ideas. New York: Basic Books, 1980.

[7] M. Resnick, A. Bruckman, and F. Martin, "Constructional Design: Creating New Construction Kits for Kids,” in The Design of Children's Technology. A. Druin ed. San Francisco: Morgan Kaufmann Publishers, Inc. pp. 149-16, 1999.

[8] A. Watters. "Lego Mindstorms: A History of Educational Robotics," 2015. http://hackeducation.com/2015/04/10/mindstorms Retrieved February 3, 2019.

[9] FIRST, Building a Community: 2017 Annual Impact Report, 2018. https://www.firstinspires.org/sites/default/files/uploads/annual-report/fy2017-annual-impactreport.pdf Retrieved February 3, 2019.

[10] J. Wakeman-Linn, and A. Perry, “A Proposal to Incorporate Lego ${ }^{\circledR}$ Mindstorms into an Introduction to Engineering Courses,” 2002. Paper presented at 2002 ASEE Annual Conference, Montreal, Canada.

[11] B. Adams, Traction and Ballasting Experiments Using Lego Mindstorms," 2005. Paper presented at 2005 ASEE Annual Conference, Portland, Oregon.

[12] M. W. Varney, A. Janoudi, D. M. Aslam, and D. Graham, "Building Young Engineers: TASEM for Third Graders in Woodcreek Magnet Elementary School." IEEE Transactions on Education, vol. 55.1, pp. 78-82, 2012.

[13] E. Cejka, C. Rogers, and M. Portsmore, M. "Kindergarten Robotics: Using Robotics to Motivate Math, Science, and Engineering Literacy in Elementary School. International Journal of Engineering Education, vol. 22.4, pp. 711, 2006.

[14] F. Barreto, V. Benitti, and N. Spolaor, "How Have Robots Supported STEM Teaching?" in Robotics in STEM Education: Redesigning the Learning Experience. M. S. Khine, ed. Cham: Springer, pp. 103-130, 2017. 
[15] C. Rogers, and M. Portsmore, M. Bringing Engineering to Elementary School. Journal of STEM Education: Innovations \& Research, vol. 5, p.18, 2004.

[16] K. B. Wendell, and C. Rogers, "Engineering Design-based Science, Science Content Performance, and Science Attitudes in Elementary School." Journal of Engineering Education, vol. 102,4, pp. 513-540, 2013.

[17] C. Hanson, "Brick by Brick: Modularity and Programmability in Mindstorms and Gaming," in LEGO Studies: Examining the Building of a Transmedial Phenomenon. M. J. P. Wolf ed. New York: Routledge. pp.153-165, 2014.

[18] S. Sontgerath, and R. N. Meadows, "A Comparison of Changes in Science Interest and Identity and 21st Century Learning Skills in a Mixed-Gender and Single- Gender Robotics Program for Elementary/Middle School Youth,” 2018. Paper presented at 2018 ASEE Collaborative Network for Engineering and Computing Diversity Conference, Crystal City, VA.

[19] M. Lachney, 2014. "Building the LEGO Classroom.” In LEGO Studies: Examining the Building of a Transmedial Phenomenon, in LEGO Studies: Examining the Building of a Transmedial Phenomenon. M. J. P. Wolf ed. New York: Routledge. Pp.166186, 2014.

[20] D. M. Riley, and J. L. Hall. 2016. "Privatization of Public Education: Lessons from New Orleans for Engineering Education in K-12 and Beyond, 2016." Paper presented at 2016 ASEE Annual Conference, New Orleans, LA.

[21] I. Roderick, Critical Discourse Studies and Technology: A Multimodal Approach to Analysing Technoculture. London: Bloomsbury Publishing, 2016.

[22] D. B. Shaw, Technoculture: The Key Concepts. London: Bloomsbury Publishing, 2008.

[23] J. Saldaña, The Coding Manual for Qualitative Researchers, Third Edition. Los Angeles: SAGE Publications, 2016.

[24] G. Biesta, "Mixed Methods in Educational Research," in Research Methods and Methodologies in Education. R. Coe, M. Waring, L. V. Hedges, \& J. Arthur eds. Thousand Oaks: SAGE Publications, pp. 159-165, 2017.

[25] J. Lambert and J. Pearson, Adventure Playgrounds. New York: Penguin Books, 1974.

[26] C. Ward, Anarchy in Action. Oakland: PM Press, 2018.

[27] S. Turkle, The Second Self: Computers and the Human Spirit. Cambridge: MIT Press, 1984.

[28] N. Noddings, Caring: A Feminine Approach to Ethics and Moral Education. Berkeley: University of California Press, 1984

[29] E. Warford, "Toward a More Caring Code of Engineering Ethics," 2018. Paper presented at 2018 ASEE Annual Conference, Salt Lake City, Utah.

[30] S. Jaffee, and J. S. Hyde, "Gender Differences in Moral Orientation: A Meta Analysis." Psychological Bulletin, vol. 126.5, pp. 703, 2000.

[31] N. Noddings, Philosophy of Education, Fourth Edition. Boulder: Westview Press, 2016.

[32] J. Rhee, The Robotic Imaginary: The Human and the Price of Dehumanized Labor. Minneapolis: University of Minnesota Press, 2018.

[33] D. Kakoudaki, Anatomy of a Robot: Literature, Cinema, and the Cultural Work of Artificial People. New Brunswick: Rutgers University Press, 2014.

[34] Y. B. Kafai, and Q. Burke, Connected Code: Why Children Need to Learn Programming. Cambridge: MIT Press, 2014.

[35] M. Ford, Rise of the Robots: Technology and the Threat of a Jobless Future. New York: Basic Books, 2015.

[36] J. Galliott, Military Robots: Mapping the Moral Landscape. New York: Routledge, 2016.

[37] D. D. Noble, The Classroom Arsenal: Military Research, Information Technology and Public Education. London, UK: Falmer Press, 1991.

[38] S. Vossoughi, and S. Vakil, "Towards What Ends? A Critical Analysis of Militarism, Equity and STEM Education," in Education at War: The Fight for Students of Color in America's Public Schools. A. I. Ali \& T. L. Buenavista eds. New York, NY: Fordham University Press, pp. 117-140, 2018.

[39] S. A. Seldon, and O. Adiboye, The Fourth Education Revolution: Will Artificial Intelligence Liberate or Infantilize Humanity. Buckingham: University of Buckingham Press, 2018. 